\title{
EFECTO DE TRES CONCENTRACIONES DE Heterorhabditis sp. EN EL CONTROL DE Ceratitis capitata Wiedemann EN CONDICIONES DE LABORATORIO
}

\section{EFFECT OF THREE CONCENTRATIONS OF Heterorhabditis sp. IN THE CONTROL OF Ceratitis capitata Wiedemann UNDER LABORATORY CONDITIONS}

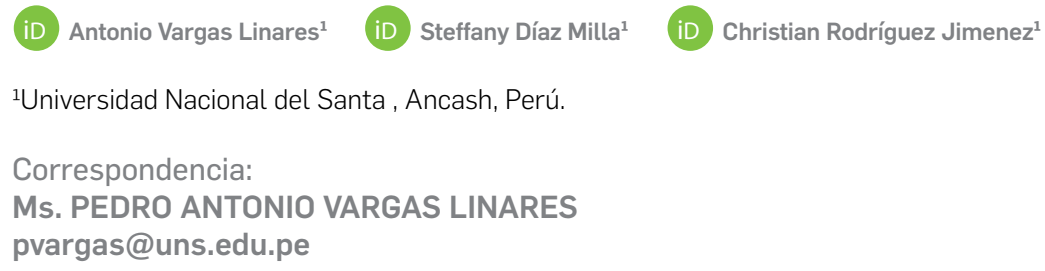

\section{RESUMEN}

La investigación tuvo como objetivo evaluar el efecto de tres concentraciones del nematodo entomopatógeno Heterorhabditis sp. en el control de la mosca mediterránea de la fruta (Ceratitis capitata Wiedemann) en condiciones de laboratorio. Para tal fin se evaluaron tres concentraciones Heterorhabditis sp. ( $T_{1}: 3000, T_{2}: 5000$ y $T_{3}: 7000 \mathrm{Jls} /$ $\mathrm{ml}$ ). Se utilizó el diseño completamente al azar (DCA), empleando 4 tratamientos con 4 repeticiones, considerándose un testigo por repetición. Cada unidad experimental contuvo 15 larvas de la Ceratitis capitata Wiedemann. Se realizaron evaluaciones a los 10, 13 y 16 días después de inoculado (ddi) las unidades experimentales con las concentraciones del nemátodo entomopatógeno. Se evaluaron las larvas y pupas parasitadas por Heterorhabditis sp.; asimismo, se contaron el número de nematodos juveniles infectivos por larvas y por pupa. Como resultado se encontró el tratamiento T3 (7000 Jls/ml) ejerció mejor control de las moscas de la fruta, con una mortandad de $76.7 \%$; seguido del tratamiento T2 (5000 Jls/ml), con una mortandad de $65.0 \%$; el menor control se obtuvo con el tratamiento T1 (3000 Jls/ml), con una mortandad igual a 48.3 \%. Se concluyó que a mayor concentración de Heterorhabditis sp., mejor nivel de control de Ceratitis capitata, a nivel de larvas y pupas.

Palabras clave: Nematodo entomopatógeno, Heterorhabditis sp., control, mortandad.

\section{ABSTRACT}

The objective of the research was to evaluate the effect of three concentrations of the entomopathogenic nematode Heterorhabditis sp. in the control of the Mediterranean fruit fly (Ceratitis capitata Wiedemann) under laboratory conditions. For this purpose, three concentrations Heterorhabditis sp. ( $T_{1}: 3000, T_{2}: 5000$ and $T_{3}: 7000 \mathrm{Jls} / \mathrm{ml}$ ). The completely randomized design (DCA) was used, employing 4 treatments with 4 repetitions, considering a control per repetition. Each experimental unit contained 
15 larvae of Ceratitis capitata Wiedemann. Evaluations are made at 10, 13 and 16 days after inoculation (ddi) the experimental units with the concentrations of the entomopathogenic nematode. The larvae and pupae parasitized by Heterorhabditis sp.; Likewise, the number of infective juvenile nematodes per larvae and per pupa will be counted. As a result, it was found that the T3 treatment (7000 Jls / ml) exerted better control of the fruit flies, with a mortality of $76.7 \%$; followed by T2 treatment (5000 Jls / ml), with a mortality of $65.0 \%$; the lowest control was obtained with the $\mathrm{T} 1$ treatment (3000 Jls / $\mathrm{ml}$ ), with a mortality equal to $48.3 \%$. It was concluded that the higher the concentration of Heterorhabditis sp., the better the level of control of Ceratitis capitata, at the larval level.

Key words: Entomopathogenic nematode, Heterorhabditis sp., control, mortality.

\section{INTRODUCCIÓN}

\section{Las Moscas de la fruta}

Las moscas de la fruta constituyen una de las plagas más devastadoras de la producción frutícola en el Perú y el mundo; al respecto SENASA (2016), indica que, la mosca mediterránea de la fruta (Ceratitis capitata Wiedemann), es una de las principales plagas que limitan el acceso de frutas frescas a mercados internacionales, por lo que los países importadores aplican medidas fitosanitarias muy estrictas para mitigar el riesgo del ingreso de dicha plaga a sus mercados.

Varios autores coinciden indicando que, las moscas de la fruta causan daños físicos directos en la pulpa de las frutas, producidos por las larvas y daños secundarios causados por la entrada de microorganismos patógenos, además de implicaciones indirectas tales como las medidas cuarentenarias y los tratamientos de postcosecha (ICA, 2005).

Según el Programa Nacional de Moscas de la Fruta (2001, citado por Hernández, 2016), afirman que Ceratitis capitata Wiedemann presenta una metamorfosis completa, presentando las cuatro fases de desarrollo: huevo, larva, pupa y adulto. En la fase de huevo puede durar de 2-7 días, fase larval de 6-11 días y la fase pupa de 9 - 15 días; la duración de este ciclo depende directamente de las condiciones ambientales (Servicio Nacional de Sanidad Agraria, 2001).

La mosca del Mediterráneo, Ceratitis capitata Wiedemann (Díptera: Tephritidae) es la plaga más destructiva y más distribuida de los cítricos y muchos otros frutales en el mundo. El insecto adquiere gran importancia, no solo por los daños que hace sino por su capacidad invasora, el gran número de frutales y otras plantas que ataca, así como las restricciones que impone el mercado internacional a los países con esta plaga (ICA, 1989).

El control de las moscas de la fruta se basa en los métodos de control cultural dirigido a la eliminación de estados inmaduros; control químico dirigido al control de adultos, con aplicacióndecebostóxicos; controllegal,mediante la aplicación de medidas cuarentenarias, guías fitosanitarias, certificaciones de producción, constancias técnicas de ejecución de medidas; control autocida, método consiste en la liberación periódica y controlada de individuos criados masivamente en laboratorios, individuos esterilizados y se liberados en el campo de cultivo, estos al cruzarse con las plagas nativas no podrán producir nuevas progenies (Aluja, 1993, Alfaro et al., 1998; citador por Hernández, 2016).

El control biológico de las moscas de la fruta se basa en el uso de parasitoides y entomopatógenos, siendo Jorge Compere el primer entomólogo que realizo pruebas mediante el control biológico para reducir daños por Ceratitis capitata W. a inicios del siglo XX (Gómez, 1932, citado por Hernández, 2016).

\section{Nematodos entomopatógenos}

Merino \& France, (2009), afirman que los nematodos entomopatógenos (NEPs), son unos organismos parásitos obligados de algunas plagas agrícolas de interés. Afirman, asimismo, que los nematodos reúnen características que les otorgan un potencial como agentes de control 
biológico; poseen un amplio rango de insectos huéspedes, tienen la habilidad para ubicar y perseguir en el suelo a su objetivo, entrando en él y liberando así a la bacteria simbionte e induce a la muerte del huésped dentro de las 24 a 48 horas después de haberse producido la infección, éstos nematodos se pueden reproducir masivamente y pueden ser aplicados fácilmente, son seguros para los organismos que no son su objetivo y para el medioambiente.

Dentro de esta clasificación de nemátodos entomopatógenos generalmente comprende a dos familias del orden Rhabditidos, la familia Steinernematidae y la familia Heterorhabditidae, parasitos facultativos de insectos. La familia 37 Steinernematidae comprende dos géneros: Steinernema y Neosteinernema. La familia Heterorhabditidae comprende el género Heterorhabditis (Romero, 2004).

Suarez et al., (s.f), afirman que: los dauers o juveniles infectivos penetran al hospedante por vía oral, anal, espiráculos o tráquea, en el caso de Heterorhabditis también a través del tegumento Inter segmental, si las medidas de defensa no son suficientes, los NEP terminan ingresando al hemocele donde se liberan las bacterias simbiontes a través del ano (Steinernematidos) o por la boca (heterorhabditidos), las cuales se multiplican y destruyen tejidos y hemolinfa, ocasionando la muerte del insecto por una septicemia generalizada en 24-96 horas.

Zioni et al., Nguyen \& Smart (citados por Ruiz, 2009) indican que la duración de vida de $H$. bacteriophora a $25^{\circ} \mathrm{C}$, de huevo a huevo es de $96 \mathrm{~h}$ el desarrollo de juveniles toma un tiempo de 48 h, con la duración de cada estado de 8 a 12 h la duración y proporción de los estados de desarrollo en la población son similares en cultivos in vivo que in vitro. Los ciclos de vida dependen de la temperatura y no se completa a temperaturas inferiores de $10 \circ 15^{\circ} \mathrm{C}$ superiores de 35 a $37^{\circ} \mathrm{C}$, siendo la óptima de $24^{\circ} \mathrm{C}$

Heterorhabditis bacteriophora actúa en simbiosis con una bacteria infectiva; al respecto Cortes (2009), señala que el juvenil infectivo (J1) de Heterorhabditis sp. posee la bacteria Photorhabdus luminecens (Tomas \& Poinar) como bacteria simbionte la cual se localiza en el esófago y en la porción ventricular del intestino.

Asimismo, Poinar (citado por Cortes, 2009), afirma que los juveniles infectivos una vez en el hemocele, liberan la bacteria simbionte, que coloniza, se propagan rápidamente y matan al hospedero en 48 horas por septicemia letal. Además, los insectos muertos por ese mecanismo presentan una coloración roja, rojo ladrillo, purpura, rojo carmelita

Morgan et al., (1997), menciona que la relación existente entre el entomopatógeno y la bacteria constituye un ejemplo clásico de simbiosis, la bacteria es incapaz de sobrevivir en las condiciones ambientales del suelo por lo tanto requiere del juvenil infectivo que actúa como vector y protección, siendo su casa el intestino. Asimismo, al carecer de habilidad de invasión es dependiente del nemátodo, para trasportarse dentro del hemocele del hospedero, de igual modo recibe la protección del nematodo ya que este inhibe las defensas antibacterianas del hospedero.

Paul et al., (citados por Reyes, 2003), sostienen que el nematodo recibe los beneficios de la bacteria, debido a que ésta produce una toxina que mata al hospedero rápidamente y crea un ambiente favorable para el desarrollo del nematodo al inhibir el crecimiento de microorganismos competidores como bacterias y hongos en el cadáver a través de la producción de antibióticos.

Los nematodos se alimentan de las células de la bacteria y los productos de los tejidos descompuesto del hospedero que sirven de nutrientesparasureproducción. Porconsiguiente, se producen de dos a tres generaciones antes que se desarrollen en juveniles infectivos que emergen del cadáver" (Mayta, 2011).

Por otro lado, Nicholls (2008), afirma que los nematodos entomopatógenos de los géneros Steinernema y Heterorhabditis habitan exclusivamente en el suelo y actúan eficazmente debido a que las bacterias simbióticas matan a los insectos rápidamente, no existe una íntima relación entre el huésped y el parásito. En 
consecuencia, los nematodos entomopatógenos son letales para un amplio rango de hospederos. Los nematodos entomopatógenos presentan una amplia gama hospedantes, atacando géneros de la familia lepidóptera, coleópteros y dípteros; al respecto Akhurst \& Smith (citado por Campos, 2015), indican que "Estudios en a nivel de campo y laboratorio mostraron que insectos de 17 órdenes y 135 Familias son susceptibles en algún grado a estos nematodos".

Carballo \& Guharay (citados por Angulo, 2015), el Juvenil infectivo (J1) transporta la bacteria Xenorhabdus sp. en la porción ventricular de su intestino. Después de que el nematodo ha alcanzado el hemocele, la bacteria es liberada dentro de la hemolinfa donde se propaga. Esta causa la muerte del hospedante por septicemia dentro de las 48 horas, principalmente porque al multiplicarse producen enzimas proteolíticas (destructoras de proteínas).

Actualmente el Ministerio de Desarrollo Agrario y Riego viene implementados programas de erradicación de la plaga de moscas de la fruta a nivel de la costa norte del Perú, cuya estrategia se basa en estrategias de control cultural, mecánico, control químico y control legal.

\section{MATERIALES Y MÉTODOS Lugar del estudio}

El estudio se realizó en el laboratorio de Biología y Ecología de la Facultad de Ciencias de la Universidad Nacional del Santa, ubicada en la Av. Universitaria s/n en Nuevo Chimbote, Santa - Ancash, Perú con una temperatura media de $25 \pm 2{ }^{\circ} \mathrm{C}$ y humedad relativa de $67 \pm 2 \%$, durante el periodo comprendido entre los meses de diciembre a febrero del 2019.

\section{Diseño experimental y tratamientos en estudio.}

Para el experimento se utilizó el Diseño Completo al Azar (DCA), con cuatro repeticiones. Se experimentó con tres concentraciones de Heterorhabditis sp. más un testigo por repetición. Los tratamientos en estudios se detallan en la Tabla 1.

\section{Tabla 1}

Detalle de los tratamientos estudiados

\begin{tabular}{cc}
\hline Tratamientos & Concentración \\
\hline $\mathrm{T}_{0}$ (testigo) & $0 \mathrm{JIs} / \mathrm{ml}$ \\
$\mathrm{T}_{1}$ & $3000 \mathrm{JIs} / \mathrm{ml}$ \\
$\mathrm{T}_{2}$ & $5000 \mathrm{JIs} / \mathrm{ml}$ \\
$\mathrm{T}_{3}$ & $7000 \mathrm{JIs} / \mathrm{ml}$ \\
\hline
\end{tabular}

Nota: JIs. Juveniles infectivos.

Obtención del material biológico - larvas. Las larvas de la mosca mediterránea de la fruta (Ceratitis capitata Wiedemann) fueron obtenidas de frutos infestados, para lo cual se siguieron los procedimientos de recolección establecidos en el Manual del Sistema Nacional de Vigilancia de Moscas de la fruta del Servicio Nacional de Sanidad Agraria - SENASA (2007), que consistió en la recolección de frutos maduros de pomarrosa, ají escabeche y mango con síntomas de posturas de mosca de la fruta. Los frutos fueron colectados en bolsa plástica para después ser llevadas al laboratorio $\mathrm{N}^{\circ} 3$ de
Biología y Ecología de la Facultad de Ciencias de la UNS.

\section{Separación, determinación y contabilización de larvas}

Los frutos maduros infestados fueron disectados, separando con pinzas las larvas de la pulpa de la fruta, luego se determinó a través del estereoscopio los especímenes de Ceratitis capitata Wiedemann, siguiendo las características morfológicas descritas por el SENASA (2015); se seleccionaron las larvas del tercer estadio, para ser colocadas en placas 
Petri, en cantidad de 15 larvas para ser lavadas con agua destilada y posterior distribución por tratamiento.

Obtención de nematodos entomopatógenos.

Los nematodos fueron obtenidos de larvas de Galleria mellonella Linnaeus infectadas con el nematodo entomopatógeno Heterorhabditis sp. a través de la Sub Dirección de Control Biológico (SDCB-SENASA, Sede ATE, Lima). Las larvas de Galleria mellonella Linnaeus fueron colocadas en trampas White para separar los nematodos de su interior. Estas trampas White fueron adaptadas por Woodring y Kaya (citado por Reyes, 2003), y consistieron en 2 tapas de placa Petri una de $5.3 \mathrm{~cm}$ de diámetro invertida sobre la otra de $9.2 \mathrm{~cm}$ a las que se colocaron encima una doble de pieza de papel filtro húmeda vertiendo agua destilada en la placa de mayor diámetro evitando que entre en contacto con la superficie de la placa de menor diámetro donde se ubicaron las 3 larvas infectadas. Asimismo, las trampas se incubaron a $25 \pm 2{ }^{\circ} \mathrm{C}$, siguiendo la metodología de Woodring y Kaya (citado por Reyes, 2003).

La obtención de los nemátodos se ejecutó cada 24 horas (tres cosechas), a partir de la emergencia de los juveniles infectivos del cadáver de la larva de Galleria mellonella Linnaeus, se cosechó y almacenó la solución con nematodos en un vaso precipitado y se añadió agua destilada utilizando una piseta con el fin de regular la concentración y facilitar el conteo.

\section{Contabilización de nemátodos.}

Para la contabilización de los nemátodos se utilizó el método de la dilución volumétrica (Leucoma, citado por Mayta, 2011). Donde, empleando una micropipeta de $10 \mu \mathrm{l}$ se extrajo de la solución del vaso precipitado cinco micro gotas que fueron colocadas en una placa Petri de plástico cuadriculada, en la que se contó el número de nematodos viables usando un Estereoscopio binocular de 40X-1000X y un contómetro para mayor precisión. Para determinar las concentraciones del nematodo entomopatógeno Heterorhabditis sp. por mililitro a extraer de la solución y proporcionarla por cada tratamiento: 0 (control), 3000, 5000 y 7000 juveniles infectivos, se hizo uso de la fórmula utilizada por Quinteros (2003) y recomendadas por la SDCB - SENASA, Lima; que se especifica a continuación:

$X=(b * 10 u l / a) * c$

Dónde: $\mathrm{a}=$ número de nematodos promedio en $10 \mu \mathrm{l} ; \mathrm{b}=$ número de nematodos deseado según tratamiento (concentración); c = $1 \mathrm{ml} / 1000 \mathrm{ul}$, factor de conversión de ul a $\mathrm{ml} ; \mathrm{X}=$ Volumen restante del mililitro que le corresponde a cada tratamiento. Luego, a cada concentración del nematodo entomopatógeno Heterorhabditis sp. contenidos en un $1 \mathrm{ml}$ se diluyó en $9.0 \mathrm{ml}$ de agua destilada formando una nueva dilución de $10 \mathrm{ml}$ (1 en 9) aplicable según a cada uno de los tratamientos.

\section{Sustrato de los tratamientos}

El sustrato empleado fue arena y humus a una proporción 2:1 (arena:humus). El sustrato fue tamizado y esterilizado con estufa a una temperatura de $120^{\circ} \mathrm{C}$ por 3 horas. El sustrato tamizado y esterilizado se colocó en las macetas de plástico a una proporción de 250 g/maceta, agregando un volumen de agua destilada para completar la capacidad de campo del sustrato (25\% de humedad), manteniendo esta humedad durante el tiempo de investigación.

\section{Inoculación del nemátodo entomopatógeno Heterorhabditis sp.}

En cada maceta se incorporaron 15 larvas del tercer estadio de la mosca mediterránea de la fruta (Ceratitis capitata Wiedemann). Luego, a cada maceta según el tratamiento que le correspondía se le inoculó las concentraciones del nemátodo entomopatógeno Heterorhabditis $s p$. contenidos en los $10 \mathrm{ml}$ de la nueva dilución y se distribuyó homogéneamente por todo el sustrato que contenía las larvas de C. capitata Wied. usando un aspersor; al tratamiento control solo se agregó agua destilada siguiendo la metodología planteada por Lezama et al. (1996). Las macetas fueron cubiertas con las tapas de plástico a una temperatura ambiente de $25 \pm 2{ }^{\circ} \mathrm{C}$.

\section{Evaluación. \\ Porcentaje de mortandad}

Se evaluó la mortandad de larvas y pupas de Ceratitis capitata Wiedemann, mediante 
la metodología de Castellón, Gonzáles \& Pozo (2014), causada por las distintas concentraciones de juveniles infectivos del nematodo entomopatógeno Heterorhabditis sp., consiguiendo al final del experimento el número acumulado de individuos muertos en 3 días de evaluación. El porcentaje de larvas y pupas de la mosca mediterránea de la fruta (Ceratitis capitata Wiedemann) que presentaron mortandad se determinó empleando la fórmula desarrollada por Duso et al., (citado por Barrera, et al., 2013): \% M = NMF / NVI * 100

Donde: $\% M=$ Porcentaje de mortalidad del tratamiento; NMF = Número de individuos muertos al final del tratamiento; NVI = Número de individuos vivos antes del tratamiento.

\section{Conteo de nematodos por larva y pupa infectada}

Se seleccionaron al azar 3 larvas y/o pupas de Ceratitis capitata Wiedemann infectadas de las trampas White instaladas para la evaluación de mortandad, se procedió disectar las larvas muertas para contar el número de nematodos emergidos de cada larva o pupa, asegurando la de todos los nemátodos del cuerpo de la larva muerta; se utilizó el mismo procedimiento descrito para la contabilización de nemátodos en larvas de Galleria mellonella L.

\section{RESULTADOS}

Efecto de Heterorhabditis sp. en la mortandad de larvas y pupas de Ceratitis capitata W.

\section{Tabla 2}

Porcentaje total de especímenes muertos por cada tratamiento

\begin{tabular}{ccccc}
\hline Repeticiones & $\mathrm{T}_{0}$ & $\mathrm{~T}_{1}$ & $\mathrm{~T}_{2}$ & $\mathrm{~T}_{3}$ \\
\hline Repetición 1 & 6.7 & 46.7 & 60.0 & 73.3 \\
Repetición 2 & 6.7 & 53.3 & 66.7 & 73.3 \\
Repetición 3 & 0.0 & 46.7 & 66.7 & 80.0 \\
Repetición 4 & 6.7 & 46.7 & 66.7 & 80.0 \\
Promedio & 5.0 & 48.3 & 65.0 & 76.7 \\
\hline
\end{tabular}

Tabla 3

Porcentaje de mortandad promedio a nivel de larva y pupas por tratamientos

\begin{tabular}{ccccc}
\hline Estadio & $\mathrm{T}_{0}$ & $\mathrm{~T}_{1}$ & $\mathrm{~T}_{2}$ & $\mathrm{~T}_{3}$ \\
\hline Larva & 5 & 18.33 & 28.33 & 36.66 \\
Pupa & 0.0 & 30.00 & 36.66 & 40.00 \\
\hline
\end{tabular}


Tabla 4

Análisis de varianza para porcentaje de especímenes muertos por tratamiento

\begin{tabular}{crrrrr}
\hline $\begin{array}{c}\text { Fuentes de } \\
\text { variabilidad }\end{array}$ & $\begin{array}{c}\text { Suma de } \\
\text { cuadrados }\end{array}$ & gl & \multicolumn{1}{c}{$\begin{array}{c}\text { Media } \\
\text { cuadrática }\end{array}$} & F & Sig. \\
\hline Tratamientos & 11821,283 & 3 & 3940,428 & 326,341 &, 000 \\
Error & 144,895 & 12 & 12,075 & & \\
Total & 11966,178 & 15 & & & \\
\hline
\end{tabular}

Tabla 5

Prueba múltiple de Duncan para porcentaje de especímenes muertos

\begin{tabular}{cccccc}
\hline \multirow{2}{*}{ Tratamientos } & $\mathrm{N}^{\circ}$ & \multicolumn{5}{c}{ Subconjunto para alfa $=0.05$} \\
& & 1 & 2 & 3 & \multicolumn{1}{c}{4} \\
\hline $\mathrm{T}_{0}$ & 4 & 5,025 & & & \\
$\mathrm{~T}_{1}$ & 4 & & 48,350 & & \\
$\mathrm{~T}_{2}$ & 4 & & & 65,025 & \\
$\mathrm{~T}_{3}$ & 4 & & & & 76,650 \\
Sig. & & 1,000 & 1,000 & 1,000 & 1,000 \\
\hline
\end{tabular}

Número de nematodos por larva y pupa de Ceratitis capitata W.

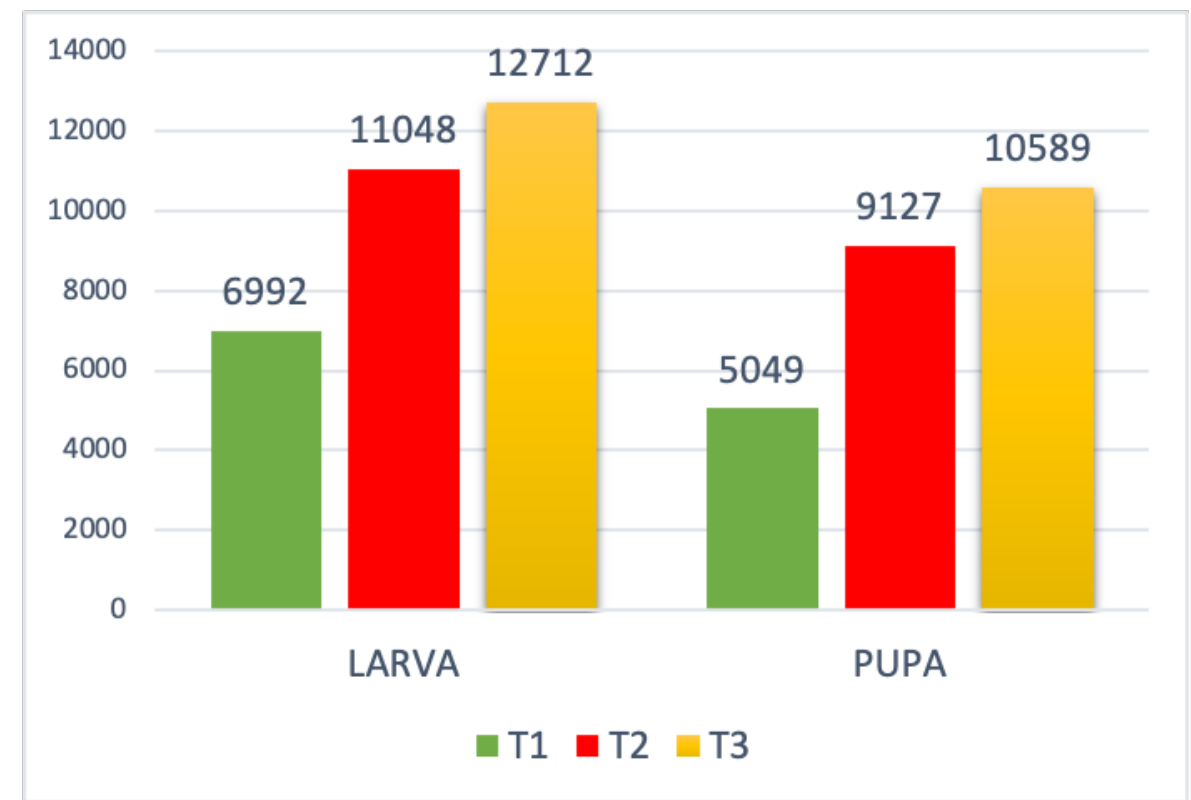

Figura 1. Número promedio de Heterorhabditis sp. por larva y pupas muertas. 


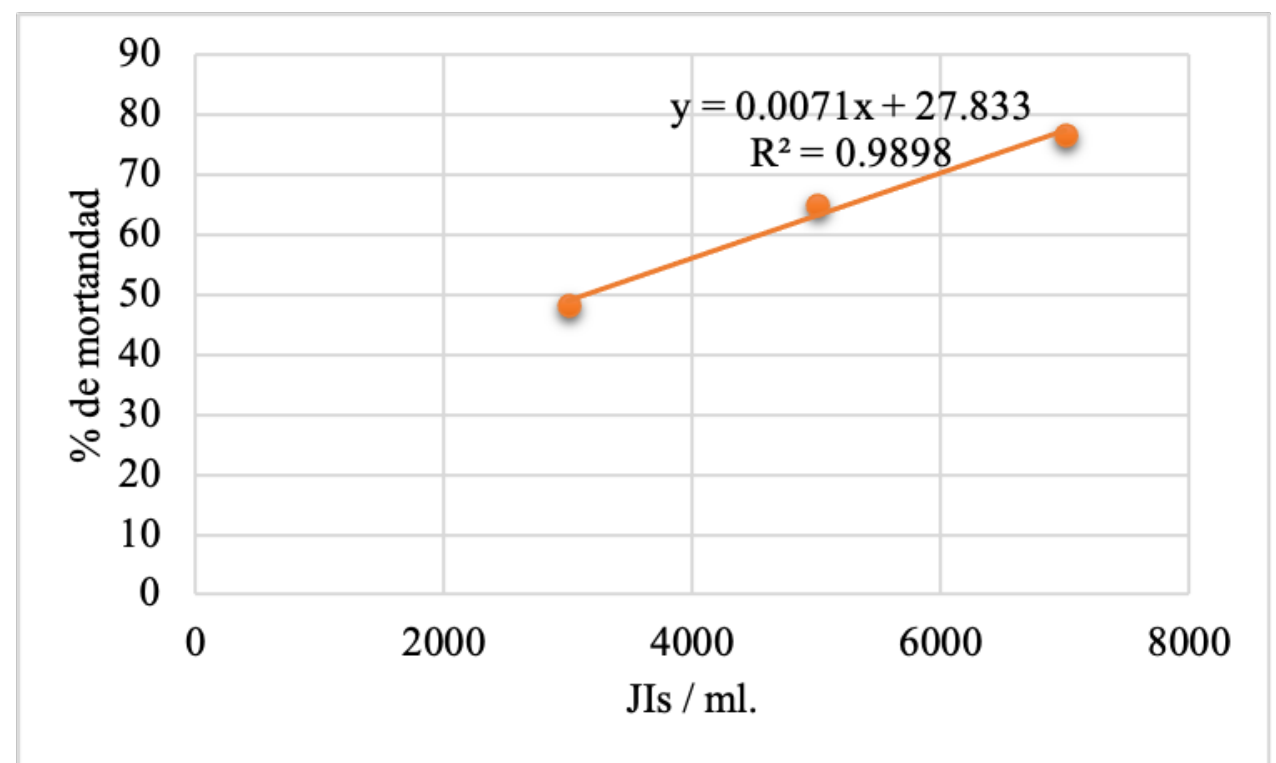

Figura 2. Correlación concentración Jls y \% de mortandad.

\section{DISCUSIÓN}

En la Tabla 2, se presenta el porcentaje promedio de especímenes (larvas más pupas) muertas por cada tratamiento; se aprecia que con el tratamiento T3 (7000 Jls / ml) se obtuvieron mejor control de Ceratitis capitata, a nivel de larvas y pupas, con un promedio de 76.7 \%; seguido del tratamiento T2 (5000 Jls/ $\mathrm{ml}$ ) que alcanzó un promedio de control del 65 $\%$ y el tratamiento T1 (3000 Jls/ml), con $48.3 \%$ de control.

Asimismo, se encontró diferencias estadísticas entre los tratamientos (Tabla 4), resultado que evidenció la existencia de diferentes niveles de control entre las concentraciones del nemátodo Herorhabditis sp. en el control de Ceratitis capitata a nivel de larvas y pupas. Igualmente, la prueba de múltiple de Duncan (Tabla 5), evidenció que con el tratamiento T3 $(7000$ $\mathrm{Jls} / \mathrm{ml}$ ) se obtuvieron los mejores resultados en el control de C. capitata, superando a los tratamientos T3 y T2 e incluso al testigo.

Las afirmaciones anteriores sugieren que a mayor concentración del nematodo Herorhabditis sp., mejor efecto en el control de Ceratitis capitata W., a nivel de larvas y pupas; asimismo, estos resultados se pueden explicar debido a la mayor concentración de la bacteria simbiótica del género Photorhabdus, alojada en el tracto digestivo del nematodo y que es la causante de la muerte de las larvas y pupas; estos resultados son similares a los obtenidos por Lezama et al., (1996), quienes determinaron que Heterorhabditis bacteriophora Poinar mató al $82.5 \%$; de larvas y pupas de la mosca de la fruta de la especie Anastrepha ludens L.

En la Figura 2, se aprecia que a medida que se incrementa la concentración de Jls de Heterorhabditis sp. mejora el efecto en el control de Ceratitis capitata a nivel de larvas y pupas, con lo cual evidencia que uno de los tratamientos tiene mejor efecto en el control de la plaga.

Por otro lado, al evaluar los resultados a nivel de larvas y de pupa (Tabla 3), se encontró que a nivel de pupa se obtuvieron mayor porcentaje de mortandad por efecto del nemátodo entomopatógeno Herorhabditis sp. en tanto que a nivel de larvas los porcentajes de mortandad fueron menores, en relación a las pupas; para ambos estadios biológicos de Ceratitis capitata resalta el tratamiento T3 seguido del tratamiento T2.

Del análisis anterior y las evidencias de la Tabla 3 , se explica por los cambios en la metamorfosis de Ceratitis capitata a nivel de larva estadio III (larva III), cuyo estadio inmediato es pre pupa y pupa; por lo tanto, los Jls de Herorohabditis $s p$. pudieron haber infectado a nivel de pre 
pupa, generando la muerte en el estadio de pupa en mayor proporción, toda vez que el nemátodo entomopatógeno causa la muerte del hospedante entre las 24 y 48 horas después de la infección de hospedero (Poinar, citado por Cortes, 2009).

En la Figura 1, se aprecia los resultados del conteo del número de nemátodos entomopatógenos a nivel de larvas y pupas muertas; de manera general resaltó el mayor número de nemátodos a nivel de larvas en comparación al número de nemátodos a nivel de pupas. Para ambos estadios biológicos de Ceratitis capitata resaltó el tratamiento T3, con 12712 nematodos promedio por larva y 10589 nematodos por pupa; seguido del tratamiento $\mathrm{T} 2$ y $\mathrm{T} 1$.

De la afirmación anterior y las evidencias de la Figura 1, se puede explicar por la mayor susceptibilidad de las larvas al nemátodo por las diferentes aberturas naturales morfológicos y fisiológicos que pudieron haber facilitado el mayor ingreso de los nemátodos entomopatógenos hacia el interior de las larvas de $C$. capitata W., respecto a las que lograron empupar, quienes estuvieron menos expuestas al nemátodo, pero de igual manera se produjo la infección; evidenciando lo referido por Fraenklen \& Bnaskaran, citado por Reyes (2003) donde menciona que la patogenicidad de los nemátodos en pupa es el producto de la penetración en las membranas Inter segmentales antes de que la cutícula se esclerotice.

\section{CONCLUSIONES}

En virtud de los resultados se concluye que Heterorhabditis sp. aplicados en diferentes concentraciones tuvo efecto en el control de Ceratitis capitata W., a nivel de larvas y pupas; resaltando la concentración de $7000 \mathrm{Jls} / \mathrm{ml}$ como el tratamiento con mejor performance, alcanzando un promedio de $76.7 \%$; seguido de la concentración de $5000 \mathrm{Jls} / \mathrm{ml}$, con el cual se alcanzó un 65 de control. Se concluye, asimismo, que a nivel de larvas muertas de Ceratitis capitata W. se concentra mayor número de nemátodos entomopatógenos (Heterorhabditis sp); por lo que se presume que este estadio biológico de la plaga puede ser el más susceptible al nemátodo entomopatógeno y podrías tenerse mejores resultados a nivel de campo.

\section{AGRADECIMIENTOS}

Al Servicio Nacional de Sanidad Agraria, CTD Chimbote; asimismo, al Laboratorio de Control Biológico del SENASA Lima, en especial a la Ing. Hilda Gómez Ramírez y a la Blga. Hilda Gamarra Soto. Agradecimiento a la Universidad Nacional del Santa, por habernos facilitado sus ambientes del laboratorio de Biología para ejecutar el trabajo experimental.

\section{REFERENCIAS BIBLIOGRÁFICAS.}

Angulo, K. (2015). Uso de nematodos entomopatogenos en el control biológico de insectos. Trujillo, Perú: Universidad Nacional de Trujillo. Disponible en: https://dspace.unitru.edu. pe/bitstream/handle/UNITRU/3944/ Angulo\%20Silva\%20Karla\%20Lizet. pdf? sequence $=1 \&$ isAllowed $=y$

Barrera, J., Carrascal, J., Numa, S., Rodríguez, D., \& Cantor, F. (2013). Compatibilidad de Encarsia formosa (Hymenoptera: Aphelinidae) con productos comerciales en condiciones de laboratorio. Colombia: Universidad Nacional de Colombia. Disponible en: https://www.redalyc.org/ pdf/3190/319028011003.pdf

Campos, R. (2015). Nematode pathogenesis of insects and others pests. Switzerland: Springer.

Castellón, M., Gonzáles, J., \& Pozo, E. (2014). Susceptibilidad de larvas y pupas de Typophorus nigritus F. al nematodo entomopatógeno Heterorhabditis indica Poinar. Cuba: Instituto de Investigaciones de Viandas Tropicales (INIVIT). Disponible en: http://cagricola.uclv.edu.cu/descargas/ pdf/V41-Numero_3/cag043141983.pdf

Cortes, C. (2009). Actividad entomopatógena de Beauveria bassiana, Metarhizium anisopliae y Heterorhabditis sp. sobre Prodiplosis longifila (Gagné) en condiciones de campo y laboratorio. [Tesis de grado]. Universidad Nacional de Trujillo, Trujillo, 
Perú.

Hernández, F. (2016). Etapas de la erradicación y manejo integrado de la mosca de la fruta (Ceratitis capitata W.) en la región Ica. [Tesis de grado]. Universidad Nacional Agraria la Molina, Lima, Perú. Disponible en: https://repositorio.lamolina.edu.pe/ bitstream/handle/UNALM/1783/H10H4-T.pdf? sequence $=5$ \&isAllowed $=y$

Hernández, J. (2011). Portal frutícola. Una mirada a la fruticultura en Perú. Disponible en: https://www.portalfruticola.com/ noticias/2011/11/18/la-fruticultura-enperu/

Instituto Colombiano Agropecuario \& Instituto Interamericano de Cooperación para la Agricutura. (1989). Curso sobre moscas de la fruta. Antioquia, Colombia: Ministerio de Agricultura

Instituto Colombiano Agropecuario. (2005). Las moscas de la fruta. Bogotá, Colombia: Lineas Digitales Ltda. Disponible en: https://www.ica.gov.co/getattachment/ f2cd7a85-e934-418a-b294-ef04f1bbacb0/ Publicacion-4.aspx

Lezama, R., Molina, J., Contreras, O., Gonzales, M., Trujillo, A., \& Rebolledo, O. (1996). Susceptibilidad de larvas de Anastrepha ludens (Díptera: Tephritidae) a diversos nemátodos entomopatógenos (Steinernematidae y Heterorhabditidae). Colima, México: Universidad de Colima. Disponible en: https://agris.fao.org/agris-search/search. do?recordID=MX1997002848

Mayta, S. (2011). Patogenicidad de Heterorhabditis sp. y algunos hongos entomopatógenos en Anomala testaceipennis Blanchard, 1850 (Coleoptera - Scarabaeidae) bajo condiciones de laboratorio. [Tesis de grado]. Universidad Nacional Agraria La Molina, Lima, Perú.

Merino, L., \& France, A. (2009). Nemátodos entomopatógenos: Control biológico de insectos plaga de importancia económica. Chillán, Chile: Instituto Nacional de Investigación Agraria

Morgan, J., Kunzenlman, V., Tavenor, S., Ousley, M., \& Winstanley, C. (1997). Survival of Xenorhabdus nematophilus and Photorhabdus luminiscens in water and soil. United Kingdom: Journal of Applied Microbiology. DOl: https://doi.org/10.1046/ j.1365-2672.1997.00281.x

Nicholls, C. (2008). Control biológico de insectos: un enfoque agroecológico. Medellín, Colombia: Universidad de Antioquía.

Quinteros, M. (2003). Comparacion en laboratorio de la patogenicidad de tres especies nativas de nematodos entomopatógenos (rhabditida) sobre larvas de tercer instar de Phyllophaga menetriesi (Blanchard) (Coleoptera: Scarabaeidae). Colombia: Universidad del Valle. Disponible en: http:// ciat-library.ciat.cgiar.org/articulos_ciat/ ipm/pdfs/Tesis_MPQuintero.pdf

Poinar GO. (2012). History of Entomopathogenic Nematology. The Journal of Nematology. Disponible en: https://www.ncbi.nlm.nih. gov/pmc/articles/PMC3578475/

Reyes, M. (2003). Patogenicidad de nematodos entomopatógenos (Nemátoda: Steinemematidae, Heterorhabditidae) en larvas y pupas de mosca de la fruta Anastrepha ludens. [Tesis de grado]. Universidad de Colima, Tecomán, México.

Romero, F. (2004). Manejo integrado de Plagas: Las bases, losconteptos, sumercantilización. Tezcoco, Mexico: Universidad Autónoma Chapingo. Disponible en: http://agro.unc. edu.ar/ -biblio/Manejo\%20de\%20Plagas. pdf

Ruiz, F. (2009). Mejoramiento a la tolerancia al calor y a la desecación de tres nemátodos entomopatógenos. [Tesis de grado]. Instituto Politécnico Nacional, Oaxaca, Mexico. Disponible en: https://tesis.ipn.mx/ handle/123456789/4459 
Servicio Nacional de Sanidad Agraria. (2001). Manual del sistema nacional de detección de moscas de la fruta. Perú: SENASA.

SENASA. (2016). Áncash: Control integrado de mosca de la fruta. Disponible en: https:// www.senasa.gob.pe/senasacontigo/ ancash/ 